\title{
EDUCAÇÃO EM SOLO NA PÓS GRADUAÇÃO EM ENSINO TECNOLÓGICO
}

\author{
Jean Dalmo de Oliveira Marques \\ E-mail: jdomarques@hotmail.com \\ Instituto Federal de Educação, Ciência e Tecnologia do Amazonas \\ DOI: $10.15628 /$ rbept.2020.11218
}

Artigo submetido em: set/2020 e aceito em: dez/2020

\begin{abstract}
RESUMO
Este artigo investigou como a educação em solo tem sido desenvolvida na Pós Graduação em Ensino Tecnológico, compreendendo a relação teoria e prática no desenvolvimento das pesquisas científicas desenvolvidas. Assim, foram analisadas as dissertações defendidas no período de 2015 à 2020, que abordaram a temática solo direta ou indiretamente, no Programa de Pós Graduação em Ensino Tecnológico (PPGET). A Educação em Solo no PPGET é representada por pesquisas científicas e produtos educacionais aplicados a educação básica e superior com caráter investigativo, problematizador, exploratório e interdisciplinar, valorizando a teoria e prática. Os produtos educacionais apresentam características regionais contextualizados ao Bioma Amazônia em consonância com os problemas e exigências da sociedade contemporânea.
\end{abstract}

Palavras-chave: Ciência do solo. Educação profissional. Ensino tecnológico. Produto educacional.

\section{EDUCATION SOIL AT THE GRADUATE IN TECHNOLOGICAL TEACHING}

\begin{abstract}
This article investigated how the soil education has been developed at the Graduate in Technological Teaching, understanding the relation between theory and practice in the development of the developed scientific researches. Thus, were analyzed the dissertations that approached the soil theme directly or indirectly defended in the period from 2015 to 2020, in the graduate Program in Technological Teaching (GPTT).The Solo Education in GPTT is represented by scientific research and educational products applied to basic and higher education with an investigative, problematizing, exploratory and interdisciplinary character, valuing theory and practice. Educational products have regional characteristics contextualized to the Amazon Biome in line with the problems and demands of contemporary society.
\end{abstract}

Keywords: Soil science. Professional education. Technological teaching. Educational product.

\section{INTRODUÇÃO}

O solo está presente nos nossos dias e assume diversos conceitos e funções conforme a interpretação que é dada a ele. Para este estudo será considerado como o recurso natural que faz parte do meio ambiente e tem importância para as mais diversas áreas do conhecimento e profissões. Assim, 
sua Educação formal e não formal torna-se imprescindível seja na educação básica, superior e pós-graduação. Nessas diferentes modalidades de ensino, torna-se necessário a utilização de diferentes formas de abordagens bem como recursos e estratégias pedagógicas adequadas.

O estudo formal da Ciência do Solo é um departamento relativamente recente no meio acadêmico (BREVIK et al., 2014). Embora o estudo de outras ciências como biologia, química e física encontrarem-se sendo discutidas há centenas de anos nas mais diversas universidades, o estudo científico dos solos, por exemplo, data apenas para o final dos anos 1800 (BREVIK; HARTEMINK, 2010). Souza e Matos (2012) destacam a importância da Educação em Solos contemplar o solo no contexto dos sistemas dinâmicos. Isso porque este é um elemento essencial à vida, tanto por sua capacidade de produção de alimentos, além de outras atividades que desenvolvemos sobre o mesmo.

É importante considerar neste artigo a diferença entre educação e ensino. A Educação é uma prática social e um fenômeno cultural específico, objeto de investigação e estudo interdisciplinar no âmbito das Ciências Humanas, caracterizando-se também como um campo de conhecimento próprio, reconhecido tanto nacional quanto internacionalmente. Assim, a Educação compreende o ensino, mas o transcende como projeto de formação e, dessa forma, os conteúdos ensinados/aprendidos ganham sentido na interação com as experiências vividas na escola e fora dela (BRASIL, 2016), valorizando a transmissão dos valores necessários ao convívio, manutenção e desenvolvimento da sociedade como um todo. No sentido mais amplo, educação vai além do ensinar, envolve a provisão de possibilidades de autoconhecimento e valores éticos, já o ensino centra-se na transmissão de conhecimento (MARQUES; OLIVEIRA, 2016).

Nessa perspectiva, a Educação em Solo tem o intuito de sensibilizar o máximo de pessoas em relação ao solo, promovendo sempre o interesse para sua conservação, uso e ocupação sustentável, além de buscar inspirar pessoas no descobrimento de sua essência (MEGONIGAL et al., 2010). Além disso, deve ser constituída de princípios que incluam a unicidade do solo, o sentimento pelo trabalho, a aprendizagem ativa, conexões, sistemas, comunicação, problemas autênticos, feedback e avaliação. Os resultados decorrentes da aplicação destes princípios podem fazer os alunos tornarem-se eficazes na identificação, compreensão e aplicação das características únicas da ciência do solo, no papel, no contexto e nas relações desta ciência para com as demais disciplinas e da sociedade como parte de sistemas interrelacionados, reforçando o desenvolvimento pessoal e a aprendizagem ao longo da vida (FIELD et al., 2011). Apesar de muitos desses alunos não possuírem a pretensão de serem profissionais da área de solos, a Educação em Solo é uma oportunidade para mostrar a estes a importância de compreender como ele se comporta. 
Portanto, é uma ferramenta para sensibilizar as pessoas, a fim de construir as alternativas para a redução de impactos ambientais, como expressa Muggler et al. (2006). A importância de pesquisar a educação em solo nas escolas está conectada ao fato de que, na maioria das vezes, os problemas ambientais estão associados diretamente com a fragmentação do conhecimento. Esta temática é trabalhada por muitos professores de maneira superficial e os alunos percebem o meio ambiente apenas associado aos elementos naturais, algo intocável, de qual eles não fazem parte (OLIVEIRA; MARQUES, 2017; BOTELHO et al., 2019). Oliveira et al. (2017) ressaltam a necessidade do uso do solo como ferramenta para conscientização da conservação deste e dos demais recursos naturais, criando-se na população um sentimento de patrimônio coletivo e necessário para manter a sua qualidade.

A partir deste contexto, entende-se que devemos procurar estimular os alunos discutindo os processos da natureza e suas relações com a vida das pessoas (BRASIL, 2007). Segundo Biondi e Falkowski (2009) a educação em solo é um instrumento valioso para promover a conscientização ambiental, ampliando a percepção, cuja importância é normalmente desconsiderada e pouco valorizada. Para se formar cidadãos ativos, aptos a participar de ações de conservação e recuperação do meio ambiente, são requisitados mais que simples conhecimentos populares; são necessários conhecimentos e consciência técnico-científica ligados aos numerosos e complexos processos ambientais (PRAIA; GIL-PÉREZ; VILCHES, 2007).

A educação é a forma mais eficaz para alcançar uma gestão de recursos ambientais equilibrada, pois possui a capacidade de desenvolver ações educativas numa perspectiva de construir novas olhares, valores educacionais e éticos nos alunos e na sociedade (LIMA; MARQUES, 2019). Para isso, tornase necessário o desenvolvimento de uma consciência pedológica, a partir de um processo educativo que privilegie uma concepção de sustentabilidade na relação homem-natureza. As definições e conceituações sobre a importância do solo para nossa vida, no âmbito formal e informal, é assim uma maneira de oportunizar a conscientização ambiental das pessoas através da educação ambiental. Existem, por sua vez, múltiplas formas, tempos e espaços de se educar para o meio ambiente.

Embora já existam diversos espaços por todo o país que se articulam para potencializar a educação de solos e disseminar os seus conhecimentos, a sensibilização e o despertar de um pensamento crítico que o relacione a temática ambiental ainda é incompleto e pouco valorizado (OLIVEIRA et al., 2017). Nesse contexto, a escola é vista como ambiente propício a esta transformação. O despertar do conhecimento sobre solo é fundamental (LELIS et al., 2007), pois em geral, as pessoas não possuem percepção completa do meio ambiente, do funcionamento integrado de seus componentes. 
É notório que o Brasil tem reconhecimento mundial na área de Ciência do Solo, em especial pela sua contribuição em pesquisas sobre solos tropicais que se refletem no aumento na produtividade das culturas e na viabilização das novas fronteiras agrícolas, com retorno efetivo na produção de riquezas e no desenvolvimento do agronegócio. A maior parte do conhecimento de alto nível sobre solos gerado no país deve ser creditada aos programas de pósgraduação em Ciência do Solo e à interação destes com outros programas e com instituições de pesquisa nas várias regiões. Como produtos se destacam a geração de dissertações e teses e o próprio treinamento dos pesquisadores e docentes. Além disso, a sociedade cada vez mais deposita nos profissionais das Ciências Agrárias a responsabilidade para com a qualidade do ambiente e com o uso adequado dos recursos naturais. Para continuar sua efetiva contribuição ao desenvolvimento do país, a pós-graduação em Ciência do Solo precisa qualificar especialistas acadêmicos e profissionais capazes de atender diferentes seguintes demandas (CERETTA; DOS ANJOS; SIQUEIRA, 2008).

Torna-se evidente na Educação em Solo a forte relação com o trabalho, numa perspectiva teórica e prática para a formação de profissionais qualificados para atender as necessidades da sociedade. Segundo Saviani (2007), a relação entre trabalho e educação é uma relação de identidade, o que se deve pela própria necessidade humana de sobrevivência já que o homem aprendia a produzir sua existência no próprio ato de produzi-la e, através do relacionamento uns com os outros, educavam-se e educavam as novas gerações. Nesse processo, os elementos que apresentassem eficácia necessitavam ser preservados e transmitidos às novas gerações, garantindo a continuidade da espécie. O que pode ser entendido como processo educativo, onde a origem da educação coincide com a origem do homem. (SAVIANI, 2007).

Essa tendência é bem evidenciada no campo da Educação em Solo, pois se relaciona com profissionais das mais diversas áreas do conhecimento que utilizam o solo como meio para a construção do conhecimento para a sociedade no campo da ciência e tecnologia. Além disso, por pertencer diretamente à área de Ciências Agrárias é marcante a relação trabalho, educação, tecnologia e produção como essencial para a manutenção da sobrevivência humana por meio da produção de alimentos. Essa educação também é responsável por conscientizar a sociedade sobre os impactos ambientais ocasionados no solo que prejudicam a sua existência e os serviços ambientais proporcionados por ele. A perspectiva de o Brasil ser o maior produtor de alimentos passa pela necessidade de preservar e/ou conservação o seu solo, bem como na busca de tecnologias sustentáveis para o seu uso e manejo.

É fundamental que os profissionais vinculados à área das Ciências Agrárias se preocupem não apenas com a produção, mas também com a 
qualidade dos alimentos e a conservação dos recursos naturais, o que exige que estejam preparados para considerar quão indissociável é o uso do solo e da água na exploração agrícola. Percebe-se que toda a interferência no uso do solo tem reflexos na qualidade da água e no potencial produtivo das terras (TILMAN et al., 2001). O mesmo autor ainda afirma que a Ciência do Solo passe a incorporar mais profissionais de outras áreas, pois trabalhar com solo e água, visando não apenas à produção, mas também a qualidade, a sustentabilidade e a preservação do ambiente exigem interdisciplinaridade.

\section{A EDUCAÇÃO EM SOLOS NA PÓS GRADUAÇÃO EM ENSINO TECNOLÓGICO}

A pós-graduação na área de Ciências do Solo iniciou na década de 1960 com dois cursos de mestrado, na Escola de Agricultura "Luiz de Queiroz" da Universidade de São Paulo (ESALQ/USP) e na Universidade Federal do Rio Grande do Sul (UFRGS). A distribuição dos programas de PG na área da Ciência do Solo é desigual no Brasil. Isso pode ser exemplificado

pela forte concentração de grupos de pesquisa com atuação em solos e nutrição de plantas nas regiões Sudeste e Sul (CERETTA; DOS ANJOS; SIQUEIRA, 2008).

A Ciência do Solo é uma das áreas da pós-graduação que tem proporcionado maiores retornos ao investimento em pesquisa feito pelo Brasil e sua importância será cada vez maior. Principalmente, porque no Brasil são abundantes e diversificados seus recursos naturais, especialmente solo e água, e seu uso tem forte impacto na qualidade do ambiente de uma forma global. A Ciência do Solo é a área de conhecimento que tem um papel chave na geração de conhecimento sobre o manejo do solo e da água, visando a relação mais harmoniosa do homem com o ambiente. Uma das maiores riquezas do Brasil é o solo, pela sua extensão e potencialidade para uso na agropecuária. Por esse motivo os programas de pós-graduação em Ciência do Solo têm grande responsabilidade na formação de recursos humanos e na geração de ciência e tecnologias que permitam o uso racional do solo e da água com benefícios sociais, econômicos e ambientalmente aceitáveis (CERETTA; DOS ANJOS; SIQUEIRA, 2008).

Assim, os programas de pós-graduação em Ciência do Solo cresceram muito nos últimos anos, embora concentrados nas regiões Sudeste e Sul. É fundamental a criação de novos programas nas regiões Centro Oeste, Norte e Nordeste porque nessas regiões se localizam ambientes frágeis como o bioma Cerrado, a Amazônia, a Caatinga e o Pantanal (CERETTA; DOS ANJOS; SIQUEIRA, 2008). Entretanto, é preciso haver ideias de como ensinar o conteúdo de solos em um mundo de constantes mudanças, que exige 
especificidades e apresenta divergências de experiências entre os alunos (BREVIK et al., 2014).

Como sabemos, o sistema de pós-graduação no Brasil possui reconhecimento por parte da comunidade científica, nacional e internacional. Tal reconhecimento se deve ao formato e à seriedade que as políticas públicas para a pós-graduação tomaram em termos de definições e das ações voltadas para esse setor, o que se expressou, entre outros modos, em sua expansão contínua, com qualidade, nos últimos 40 anos (SANTOS e AZEVEDO, 2009). Severino (2006) concorda com essa afirmação e diz que a pós-graduação tem contribuído valiosamente para o melhor conhecimento dos problemas que emergem de diversos âmbitos da nossa realidade e para a qualificação de expressivo quadro de profissionais nas áreas de ensino, gestão e pesquisa.

Não obstante, a Educação em Solo não tem estado restrita aos cursos de Pós Graduação em Ciência do Solo, mas sua abrangência tem sido ampliada em Cursos de Pós Graduação strictu sensu (mestrado e doutorado) Profissional Tecnológico que são oferecidos por meio de cursos e programas para profissionais graduados em diversas áreas do conhecimento, recomendados pela CAPES/MEC, ofertados por Instituições Educacionais devidamente credenciadas ou reconhecidas. Pesquisas vêm sendo desenvolvidas tendo o solo como objeto de estudo e disponibilizando para a sociedade processos e produtos que podem ser utilizados diretamente pela sociedade. Além disso, a temática solo também faz parte de conteúdo programático de disciplinas especificas que relacionam este conhecimento possibilitando a qualificação de profissionais sobre as dificuldades e desafios quanto à preservação e/ou conservação do solo no contexto amazônico.

O profissional em formação tem a capacidade de aplicar o conhecimento científico e tecnológico adquirido para atender as necessitadas contemporâneas da sociedade seja na busca de alternativas viáveis para a qualidade do solo seja para potencializar a educação em solos por intermédio de recursos e estratégias pedagógicas. Por outro lado, o produto educacional que caracteriza o Mestrado Profissional em Ensino diferenciando-o do Mestrado Acadêmico, pode ser elaborado de forma prática e regionalizada com vistas na sua aplicabilidade para solucionar problemas ambientais do solo ou ser uma alternativa viável para processos e produtos tecnológicos sustentáveis que serão utilizados para obter a qualidade de vida e qualidade ambiental.

A atual Portaria CAPES $n^{\circ} 60$ de 2019 é que regulamenta o mestrado e doutorado profissionais (BRASIL, 2019). Anteriormente, os cursos profissionais eram regulados pela portaria 으 131 de 2017 que, a partir da nova publicação, deixou de vigorar. Os cursos de pós-graduação stricto sensu profissionais obedecem às mesmas regras e exigências de autorização, reconhecimento e renovação de reconhecimento estabelecidas na Resolução CES/CNE № 7, de 11 de dezembro de 2017 (BRASIL, 2017a), dependendo necessariamente de avaliação prévia da CAPES. A Educação Profissional Tecnológica de 
Graduação e Pós-Graduação contempla cursos com características especiais. Compreende programas de pós-graduação stricto sensu (mestrado e doutorado profissional), recomendados pela CAPES/MEC, bem como cursos de pós-graduação lato sensu (especialização tecnológica), em áreas afins à graduação tecnológica, ofertados por Instituições Educacionais devidamente credenciadas ou reconhecidas. Sua especificidade reside no fato de se tratar de uma formação especializada em áreas científicas e tecnológicas, que conferem ao diplomado competências para atuar em áreas profissionais específicas (BRASIL, 2020). A relevância social, científica e tecnológica dos processos de formação profissional avançada, bem como o necessário estreitamento das relações entre as universidades e o setor produtivo, qualificando profissionais para o exercício da prática profissional avançada e transformadora de procedimentos, visando atender demandas sociais, organizacionais ou profissionais e do mercado de trabalho (BRASIL, 2017b).

Dessa forma, como exemplo prática destaca-se o PPGET (Programa de Pós Graduação em Ensino Tecnológico), nível mestrado, código do curso 12003018001P3, com área de concentração Processos e Produtos para o Ensino Tecnológico, distribuído em duas linhas de pesquisa: Linha 1: Processos Formativos de Professores no Ensino Tecnológico e Linha 2: Recursos para o Ensino Técnico e Tecnológico e, mais recentemente, o Doutorado Profissional em Ensino Tecnológico, aprovado em novembro de 2019, com a mesma área de concentração do mestrado, com duas linhas de pesquisa: Linha 1: Processos para eficácia na formação de professores e no trabalho pedagógico em contextos de Ensino Tecnológico e Linha 2: Alternativas mediadoras para eficácia do ensino e aprendizagem em contextos tecnológicos.

As constantes mudanças geradas no mundo do trabalho, advindas da economia globalizada, reestruturação de processos produtivos e alterações em postos de trabalho provocaram reformas no currículo da educação profissional e tecnológica, o ensino normativo da racionalidade técnica (conteúdos dissociados do mundo do trabalho) deu lugar ao ensino contextualizado, que tem como core a formação reflexiva e crítica para entendimento dos processos necessários, busca de dispositivos (internos) para mobilização de conhecimentos, recursos e ferramentas frente a processos de tecnologia e inovação presentes na dinâmica do desenvolvimento socioeconômico (JACON, 2017).

Nessa perspectiva, o papel do professor é imprescindível para que os objetivos propostos sejam alcançados, uma vez que existem diversas atribuições, que exigem múltiplas habilidades, as quais devem garantir que 0 processo ocorra de forma propícia, desde o planejamento até a avaliação. Quando se considera o docente que atua na Educação Profissional e Tecnológica, por exemplo, registra-se que esse profissional deve dominar a 
disciplina prática a ser ministrada, assim como precisa possuir conhecimentos na área da pedagogia. Registra-se, então, a importância da formação dos professores, para a qualidade da educação, quer seja no ensino técnico, quer seja no âmbito da pós-graduação stricto sensu (KREUTZ; WELTER, 2016; PATRUS; LIMA, 2014).

Portanto, o objetivo do presente estudo foi investigar como a educação em solo tem sido desenvolvida na Pós Graduação em Ensino Tecnológico, compreendendo a relação teoria e prática no desenvolvimento das pesquisas científicas desenvolvidas.

\section{METODOLOGIA}

A essência da pesquisa adotada neste estudo é do tipo qualitativa, de cunho exploratório e baseada num estudo de caso (YIN, 2005; STAKE, 2013). Esses destacam que o estudo de caso possibilita ao pesquisador compreender um fenômeno a partir de seu contexto real, sendo possível coletar dados por intermédio de fontes documentais, registros e observações.

Assim, foram analisados as dissertações defendidas no período de 2015 à 2020, que abordaram a temática solo direta ou indiretamente, no Programa de Pós Graduação em Ensino Tecnológico (PPGET), nível Mestrado, linha de pesquisa sobre Recursos para o Ensino Técnico e Tecnológico, do Instituto Federal de Educação, Ciência e Tecnologia do Amazonas - IFAM, Campus Manaus-Centro.

Para tanto, a sistemática de análise dos resultados da pesquisa considerou nas dissertações o (a): público alvo, objetivo, metodologia, abordagem considerada para o solo, divulgação científica e produto educacional.

\section{RESULTADOS E DISCUSSÃO}

O Quadro 1 apresenta as dissertações defendidas no período de 2015 à 2020 no Programa de Pós Graduação em Ensino Tecnológico (PPGET). Foram identificados 6 (seis) dissertações defendidas que abordaram a temática solo no seu estudo de diferentes formas tais como sumidouro de carbono (Dissertação A), importante de ser preservado, conservado (Dissertação B), compreendido por meio de experimentos em laboratório e atividades práticas no campo (Dissertação C), integrante do meio ambiente (Dissertação D), da paisagem (Dissertação $F$ ) e recurso natural (Dissertação $E$ ).

No mesmo sentido, o público alvo ao qual a pesquisa se destinou abrangeu alunos do ensino fundamental, médio, médio integrado e graduação. 
Assim, nota-se claramente que o solo é estudado em diferentes níveis de ensino e, consequentemente, de diferentes formas e em todas elas é considerado de suma importância para a manutenção do equilíbrio ambiental. Além disso, faz parte de diferentes recursos, propostas e estratégias didáticas de ensino com diferentes objetivos (Quadro 1).

Quadro 1: Dissertações defendidas no Programa de Pós Graduação em Ensino Tecnológico (PPGET) no período de 2015 à 2020.

\begin{tabular}{|c|c|c|c|c|c|c|c|}
\hline Dissertação & Ano & Título & $\begin{array}{l}\text { Público } \\
\text { alvo }\end{array}$ & Objetivo & Metodologia & $\begin{array}{l}\text { Aborda } \\
\text { gem do } \\
\text { solo }\end{array}$ & $\begin{array}{l}\text { Produ } \\
\text { to } \\
\text { educa } \\
\text { cional }\end{array}$ \\
\hline A & 2015 & $\begin{array}{l}\text { Estratégia } \\
\text { didática } \\
\text { para o } \\
\text { ensino dos } \\
\text { conhecime } \\
\text { ntos } \\
\text { relacionado } \\
\text { s às } \\
\text { mudanças } \\
\text { climáticas } \\
\text { globais. }\end{array}$ & $\begin{array}{c}\text { Alunos de } \\
\text { Graduaçã } \\
\text { o em } \\
\text { Biologia. }\end{array}$ & $\begin{array}{c}\text { Desenvol } \\
\text { ver uma } \\
\text { estratégia } \\
\text { didática } \\
\text { para o } \\
\text { processo } \\
\text { de ensino } \\
\text { aprendiza } \\
\text { gem } \\
\text { sobre a } \\
\text { temática } \\
\text { MCGs, } \\
\text { utilizando } \\
\text { as } \\
\text { potenciali } \\
\text { dades } \\
\text { dos } \\
\text { recursos } \\
\text { naturais } \\
\text { regionais } \\
\text { amazônic } \\
\text { os. }\end{array}$ & $\begin{array}{c}\text { Pesquisa } \\
\text { qualitativa } \\
\text { (OLIVEIRA, } \\
\text { 2008) com } \\
\text { atividades } \\
\text { em } \\
\text { ambientes } \\
\text { não-formais } \\
\text { de } \\
\text { aprendizage } \\
\text { m (COLLEY } \\
\text { et al., 2002). }\end{array}$ & $\begin{array}{c}\text { Sumido } \\
\text { uro de } \\
\text { carbono } \\
\text { no } \\
\text { ambient } \\
\text { e de } \\
\text { suma } \\
\text { importâ } \\
\text { ncia } \\
\text { para as } \\
\text { mudanç } \\
\text { as } \\
\text { climátic } \\
\text { as } \\
\text { globais. }\end{array}$ & $\begin{array}{c}\text { Mudan } \\
\text { ças } \\
\text { climáti } \\
\text { cas } \\
\text { globais } \\
\text { e } \\
\text { ensino } \\
\text { na } \\
\text { Amazô } \\
\text { nia: } \\
\text { uma } \\
\text { experi } \\
\text { ência } \\
\text { com } \\
\text { alunos } \\
\text { de } \\
\text { gradua } \\
\text { ção. }\end{array}$ \\
\hline B & 2017 & $\begin{array}{c}\text { Recursos } \\
\text { didáticos } \\
\text { para o } \\
\text { processo } \\
\text { de ensino- } \\
\text { aprendizag } \\
\text { em de } \\
\text { solos no } \\
\text { ensino }\end{array}$ & $\begin{array}{l}\text { Alunos do } \\
\text { ensino } \\
\text { fundamen } \\
\text { tal. }\end{array}$ & $\begin{array}{c}\text { Investigar } \\
\text { o uso de } \\
\text { recursos } \\
\text { didáticos } \\
\text { como } \\
\text { forma de } \\
\text { ampliar a } \\
\text { compreen } \\
\text { são do } \\
\text { solo de } \\
\text { forma a } \\
\text { viabilizar } \\
\text { o } \\
\text { processo }\end{array}$ & $\begin{array}{c}\text { Pesquisa } \\
\text { qualitativa } \\
\text { (BOGDAN; } \\
\text { BIKLEN, } \\
\text { 1994). }\end{array}$ & $\begin{array}{l}\text { Importâ } \\
\text { ncia da } \\
\text { sua } \\
\text { preserv } \\
\text { ação } \\
\text { e/ou } \\
\text { conserv } \\
\text { ação. }\end{array}$ & $\begin{array}{c}\text { Cartilh } \\
\text { a } \\
\text { amigo } \\
\text { s do } \\
\text { solo. }\end{array}$ \\
\hline
\end{tabular}




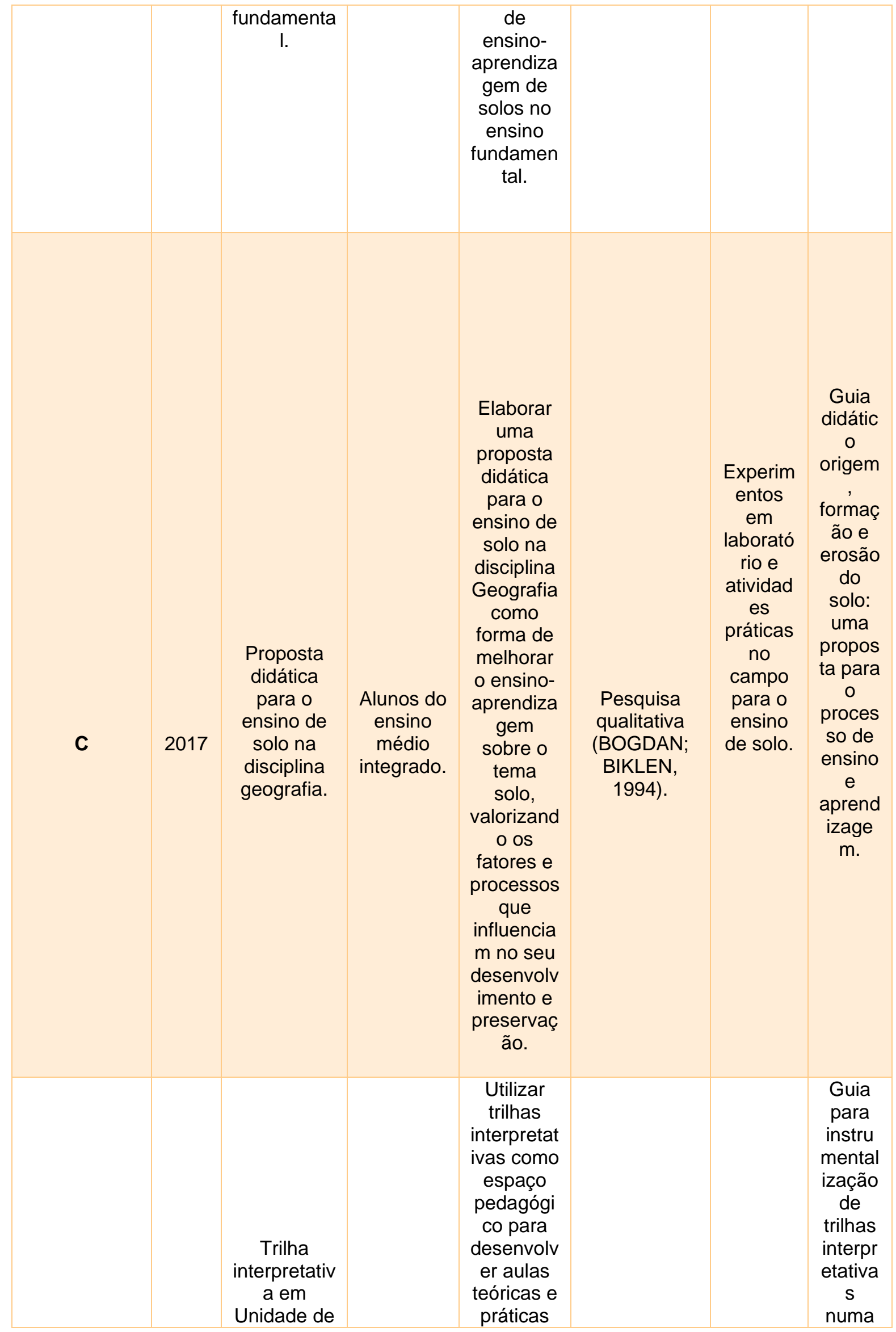




\begin{tabular}{|c|c|c|c|c|c|c|c|}
\hline D & 2018 & $\begin{array}{c}\text { Conservaç } \\
\text { ão: espaço } \\
\text { pedagógico } \\
\text { para o } \\
\text { ensino de } \\
\text { gestão } \\
\text { ambiental e } \\
\text { ecologia na } \\
\text { Amazônia. }\end{array}$ & $\begin{array}{c}\text { Alunos de } \\
\text { Graduaçã } \\
\text { o em } \\
\text { Biologia. }\end{array}$ & $\begin{array}{c}\text { sobre } \\
\text { conceitos, } \\
\text { processos } \\
\text { e } \\
\text { interaçõe } \\
\text { s } \\
\text { ecológica } \\
\text { s e } \\
\text { ambientai } \\
\text { s. } \\
\text { Promover } \\
\text { coletas de } \\
\text { solo, } \\
\text { liteira, } \\
\text { proporcio } \\
\text { nando } \\
\text { alternativ } \\
\text { a de } \\
\text { ensino e } \\
\text { aprendiza } \\
\text { do } \\
\text { contextual } \\
\text { izado com } \\
\text { a região } \\
\text { amazônic } \\
\text { a a partir } \\
\text { da } \\
\text { utilização } \\
\text { dos } \\
\text { nossos } \\
\text { recursos } \\
\text { naturais. }\end{array}$ & $\begin{array}{c}\text { Pesquisa } \\
\text { qualitativa } \\
\text { (BOGDAN; } \\
\text { BIKLEN, } \\
\text { 1994). }\end{array}$ & $\begin{array}{l}\text { Integran } \\
\text { te do } \\
\text { meio } \\
\text { ambient } \\
\text { e. }\end{array}$ & $\begin{array}{c}\text { perspe } \\
\text { ctiva } \\
\text { de } \\
\text { ensino } \\
\text { e } \\
\text { aprend } \\
\text { izage } \\
\text { m. }\end{array}$ \\
\hline E & 2018 & $\begin{array}{c}\text { Proposta } \\
\text { didática } \\
\text { para o } \\
\text { ensino de } \\
\text { meio } \\
\text { ambiente e } \\
\text { água na } \\
\text { disciplina } \\
\text { Ciências } \\
\text { Naturais. }\end{array}$ & $\begin{array}{l}\text { Alunos do } \\
\text { ensino } \\
\text { fundamen } \\
\text { tal. }\end{array}$ & $\begin{array}{c}\text { Elaborar } \\
\text { uma } \\
\text { proposta } \\
\text { didática } \\
\text { para o } \\
\text { ensino } \\
\text { dos } \\
\text { temas } \\
\text { meio } \\
\text { ambiente } \\
\text { e água na } \\
\text { disciplina } \\
\text { Ciências } \\
\text { Naturais. }\end{array}$ & $\begin{array}{c}\text { Pesquisa } \\
\text { qualitativa } \\
\text { (TRIVIÑNOS, } \\
\text { 1987). }\end{array}$ & $\begin{array}{l}\text { Recurso } \\
\text { natural } \\
\text { protetor } \\
\text { das } \\
\text { nascent } \\
\text { es. }\end{array}$ & $\begin{array}{c}\text { Propos } \\
\text { ta } \\
\text { didátic } \\
\text { a para } \\
o \\
\text { ensino } \\
\text { de } \\
\text { meio } \\
\text { ambie } \\
\text { nte e } \\
\text { água. }\end{array}$ \\
\hline $\mathbf{F}$ & 2019 & $\begin{array}{l}\text { Desvendan } \\
\text { do as } \\
\text { paisagens } \\
\text { no ensino } \\
\text { de } \\
\text { geografia a } \\
\text { partir do } \\
\text { uso e } \\
\text { ocupação } \\
\text { do solo. }\end{array}$ & $\begin{array}{l}\text { Alunos do } \\
\text { ensino } \\
\text { médio. }\end{array}$ & $\begin{array}{l}\text { Elaborar } \\
\text { uma } \\
\text { proposta } \\
\text { didática } \\
\text { sobre o } \\
\text { conteúdo } \\
\text { paisagem } \\
\text { a fim de } \\
\text { contribuir } \\
\text { para o } \\
\text { processo } \\
\text { de } \\
\text { ensino- }\end{array}$ & $\begin{array}{c}\text { Pesquisa } \\
\text { qualitativa } \\
\text { (Denzin; } \\
\text { Lincoln } \\
(2006) .\end{array}$ & $\begin{array}{c}\text { Integran } \\
\text { te da } \\
\text { paisage } \\
\text { m. }\end{array}$ & $\begin{array}{l}\text { Kit } \\
\text { pedag } \\
\text { ógico: } \\
\text { paisag } \\
\text { em à } \\
\text { vista. }\end{array}$ \\
\hline
\end{tabular}


Fonte; desenvolvido pelo autor

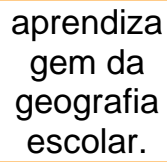

É preciso continuar os estudos na área de educação em solo, repensando e direcionando estudos e pesquisas com o intuito para a busca de metodologia que maximizem o processo de ensino-aprendizagem em solos nas instituições de ensino superior, nas escolas de ensino fundamental, médio e, acima de tudo, divulgar para a sociedade em geral (MARQUES; PAES; BOMFIM, 2015).

Conhecer as diferentes realidades deve ser uma realidade de todos aqueles que atuam na Ciência do Solo, até porque a interação é o caminho mais curto para o avanço na qualidade dos programas de pós-graduação. A visão do pesquisador deve ser de considerar que muitas vezes o que é feito em resposta a demandas mais específicas não é limitante ou de aplicação restritiva, mas é uma ótima oportunidade para avanços no conhecimento à medida que se busca o detalhe (TILMAN et al., 2001).

Em todas as dissertações analisadas foram observados a realização de atividades práticas, seja no campo como no laboratório como recurso e/ou estratégia didática para promover a construção do conhecimento sobre solo tais como experimentos sobre perfil do solo, origem do solo, formação do solo, composição do solo, cores do solo, textura do solo, erosão do solo, infiltração e retenção de água no solo. Todas as atividades aqui destacadas são conhecimentos específicos da área da Ciência do Solo e exigem habilidade do professor orientador para a condução das pesquisas. Assim, faz-se necessário repensar a prática pedagógica no sentido de problematizar o ensino do solo, alinhado à uma proposta investigativa que contribua para que o aluno valorize esse saber afim de estabelecer as relações necessárias com o contexto em que está inserido. Nesse sentido, as atividades práticas demonstraram serem mecanismos capazes de conduzir a um processo de aprendizado que desperta no aluno a sua autonomia, capacidade de crítica, raciocínio e habilidades cognitivas.

É importante notar que essa deficiência de conhecimento e enfoque é universal. Até mesmo em cursos de graduação e pós-graduação essa temática não é tão compreendida (ZINN; SKORUPA, 2015), o que demonstra a necessidade de buscar estratégias, ainda no ensino básico, para sanar a propagação dessa dificuldade de compreensão. A compreensão da sua origem e sua dinâmica precisa ser analisada por meio de sua gênese, processos e formas, ressaltando a ação de outros elementos que compõem o espaço, além de inserir o tempo, como categoria, para assim, observar as interações existentes (ALVES; SOUZA, 2015). 
Para Botelho et al. (2019), a experimentação no estudo de solos tornase necessária devido à sua complexidade; "seus estudos apenas em sala, por meio de aulas expositivas, não são suficientes para proporcionar um processo de ensino-aprendizagem eficiente para os alunos". Nessa perspectiva, presume-se que atividades práticas como os experimentos em laboratório podem viabilizar melhorias para o processo ensino-aprendizagem, pois, por natureza, são instigantes permitindo que alunos e professores realizem um ensino com possibilidades de ser problematizado e ressignificado.

Para Rieder (2014), o processo de ensino-aprendizagem pode ser muito mais eficaz se as aulas forem ministradas com o próprio objeto de estudo no ambiente onde se encontra, pois as imagens do objeto de estudo e do cenário envolvido, contribuem para que os alunos realizem associações com as informações pertinentes ao conteúdo trabalhado, isto por sua vez se fixaria mais firmemente na mente do aluno como um conhecimento novo construído. Quanto à relação professor-aluno, destacam-se alguns princípios para a boa prática na Educação, entre os quais, registram-se: o encorajamento da interação entre os sujeitos, a cooperação entre os alunos, o fornecimento de feedback, a aprendizagem ativa, e a compreensão das diferentes formas de aprendizagem (SANTOS, 2001).

Assim, teoria e prática são indissociáveis, e devem possibilitar o desenvolvimento de conhecimentos, competências e saberes profissionais articulados ao mundo do trabalho, das tecnologias e demandas socioeconômicas e ambientais (SANTOS; AZEVEDO, 2016). A atuação dos professores na educação profissional e tecnológica sobre o estudo de solos é fundamental e junto com os alunos é possível elaborar e adotar metodologias mais atrativas, com a adoção de aulas expositivas dialogadas, atividades de campo, experimentos em laboratório, entre outros. Segundo Demo (2008, p. 5), "Em educação, o desafio maior é buscar-se, à sua frente, uma empreitada quase idílica ou quixotesca, tamanho é nosso atraso. Mas há que começar".

Por isso, faz-se necessário repensar a prática pedagógica no sentido de problematizar o ensino do solo, alinhado a uma proposta investigativa que contribua para que o estudante valorize esse saber, a fim de estabelecer as relações necessárias com o contexto em que está inserido. A prática de campo de caráter investigativo, exploratório e interdisciplinar possibilitou o ensino de origem, formação, ocupação, erosão e preservação do solo de forma prática, no campo, permitindo aos estudantes compreender os processos, transformações e interações que regem essas temáticas, impossíveis de serem compreendidas apenas em sala de aula, propiciando uma experiência capaz de desvendar o ambiente no qual os alunos estão inseridos (BOTELHO; MARQUES, 2019). Botelho e Marques (2020) observaram o despertar nos alunos de atitudes, habilidades, posicionamentos e competências quanto à preservação e conservação do solo, bem como frente aos processos, dinâmicas e transformações observadas ao longo do desenvolvimento de 
atividades práticas sobre solos. Os mesmos autores ainda salientam ser necessário repensar a prática pedagógica no sentido de problematizar o ensino do solo no campo, a fim de estabelecer relações necessárias com o contexto regional favorecendo valores sociais e ambientais.

No mesmo sentido, os professores da educação profissional enfrentam novos desafios relacionados às mudanças organizacionais que afetam as relações profissionais, aos efeitos das inovações tecnológicas sobre as atividades de trabalho e culturas profissionais, ao novo papel que os sistemas simbólicos desempenham na estruturação do mundo do trabalho, ao aumento das exigências de qualidade na produção e nos serviços, à exigência de maior atenção à justiça social, às questões éticas e de sustentabilidade ambiental. São novas demandas à construção e reestruturação dos saberes e conhecimentos fundamentais à análise, reflexão e intervenções críticas e criativas na atividade de trabalho. É pressuposto básico que o docente da educação profissional seja, essencialmente, um sujeito da reflexão e da pesquisa, aberto ao trabalho coletivo e à ação crítica e cooperativa, comprometido com sua atualização permanente na área de formação (MACHADO, 2008).

$\mathrm{Na}$ atual conjuntura da formação profissional a integração dos conhecimentos teóricos e práticos, propostas indissociáveis na formação dos sujeitos, é um desafio, que se constitui em um campo fértil de investigação e reflexão crítica voltada para a relação do pensar e fazer na compreensão da realidade educativa que tem como foco específico preparar os sujeitos para o exercício de uma profissão. Nas discussões sobre a relação teoria prática, as compreensões e ações docente sobre o desenvolvimento do trabalho educativo, tornam-se aspectos importantes que ajuda a delinear como essa relação vem acontecendo no processo formativo, oportunizando um maior conhecimento das ações didático-pedagógicas dos professores que atuam na educação profissional (MORAIS; SOUZA; COSTA, 2017).

Para Rehem (2016), os desafios educacionais são graves e complexos, sobretudo, para a formação profissional, os educadores são instigados ao desenvolvimento:

[...] de uma práxis que corresponda à formação do homem novo, capaz de lidar com as características dessa época sem se desintegrar, de manter-se inteiro como pessoa e como profissional, desenvolvendo uma relação crítica com 0 conhecimento, com as relações de trabalho e da sociedade para nelas intervir criativa e autonomamente. (REHEM, 2016, p. 2). 
As pesquisas na sua totalidade são interdisciplinar e tem abordagem qualitativa e consideraram Bogdan e Biklen (1994), Denzin e Lincoln (2006) e Triviños (1987) onde os dados são obtidos a partir do contato direto do pesquisado com o objeto de estudo e mediante o qual procura entendê-lo, dar significado para o que está observando e obteve de resultado (Quadro 1). A exceção de algumas especificidades compreende-se a razão pela qual os pesquisadores ambientais utilizam a pesquisa qualitativa, visto que os deixam mais confortáveis para interagir com o ambiente, permitindo um dialogo intrínseco com o "eu" pesquisador e o objeto estudado em ambiente formal e não formal de aprendizagem. Um outro fundamento da pesquisa qualitativa é a relação com a fenomenologia, que busca compreender o significado que os acontecimentos têm para pessoas, enfatizando-se a importância da interação simbólica e da cultura para a compreensão do todo em que o pesquisador vai a campo, objetivando captar o fenômeno a partir da perspectiva das pessoas nele envolvidas.

A pesquisa qualitativa tem o potencial de proporcionar um dialogo direto entre teoria e prática, disponibilizando instrumentos e estratégias viáveis para a melhor compreensão de questões educacionais. Mayring (2002) apresenta seis delineamentos da pesquisa qualitativa: estudo de caso, análise de documentos, pesquisa-ação, pesquisa de campo, experimento qualitativo e avaliação qualitativa. A pesquisa qualitativa pode ser caracterizada por um espectro de métodos e técnicas, adaptados ao caso específico, ao invés de um método padronizado único.

A relação ensino, pesquisa e extensão continuam presentes na pós graduação em educação profissional e são de suma importância para o êxito na formação acadêmico-cientifica-profissional do aluno em formação, pois possibilita a integração de conhecimentos teóricos e práticos, permitindo orientador e orientado desenvolver e implementar produtos e processos com o intuito de solucionar problemas da sociedade.

As temáticas que constituem a pesquisa em ensino são reconhecidamente multidisciplinares e requerem enfoque interdisciplinar fazendo convergir duas ou mais áreas do conhecimento. Espera-se que a atividade interdisciplinar de pesquisa contribua para o avanço do ensino no país, a geração de conhecimentos e tecnologias, e faça surgir um profissional com formação básica, sólida e integradora. Para um mestrado profissional, a atividade de pesquisa é um grande diferencial com relação aos cursos chamados lato sensu, de extensão ou de especialização, que em essência correspondem a um aprimoramento na formação profissional (BRASIL, 2013).

No tocante a divulgação cientifica das dissertações, observou-se que a exceção da Dissertação $F$ (Disponível em: $<$ https://drive.google.com/file/d/15dRJHL7cwhCyl7r4WjPvYYP5uMNJcqc//vie $\mathrm{W}>$ ), as demais estão divulgadas e disponibilizadas no repositório institucional (RI), a saber: Dissertação A (Disponível em: Uniform Resource Identifier (URI): 
<http://repositorio.ifam.edu.br/jspui/handle/4321/58>), (Disponível em: Uniform Resource Dissertação

B <http://repositorio.ifam.edu.br/jspui/handle/4321/39>), (Disponível em: Uniform Resource $<$ http://repositorio.ifam.edu.br/jspui/handle/4321/76>), (Disponível em: Uniform Resource <http://repositorio.ifam.edu.br/jspui/handle/4321/356>) (Disponível em: Uniform Resource <http://repositorio.ifam.edu.br/jspui/handle/4321/341>). Identifier URI: Dissertação C Identifier URI: Dissertação D Identifier (URI): e Dissertação E Identifier URI:

Atualmente, o RI é considerado peça elementar no processo de comunicação científica, permitindo oportunidade para o compartilhamento da informação, e acima de tudo contribuindo para o avanço e desenvolvimento da ciência. A divulgação científica tem um papel importante para que a população adquira conhecimento sobre ciência e conheça o que está sendo realizado ao seu entorno e o quanto é importante. Além disso, é o mecanismo mais objetivo para a popularização da ciência. Percebe-se então que os repositórios são ferramentas importantes para a gestão da informação e do conhecimento nas instituições e para os envolvidos no processo de fomento à pesquisa. Por isso, torna-se importante garantir o acesso permanente e confiável da produção científica, proporcionando maior visibilidade às pesquisas desenvolvidas nas instituições (FURTADO; ESMIN; OLIVEIRA, 2014).

O sucesso da divulgação científica está associado à dedicação, responsabilidade ética e iniciativa individual que auxiliam na superação de dificuldades, aspectos primordiais para o sucesso de toda e qualquer pesquisa. A consequência disso é a transferência de conhecimentos e o desenvolvimento de habilidades que serão aplicados continuamente no aprimoramento das atividades previamente programadas, sem ignorar, contudo, a possibilidade da descoberta de talentos potenciais a serem absorvidos pela ciência, pesquisa, tecnologia e inovação do país. Enfatiza-se que todos os autores devem ser conscientes e responsáveis por sua produção e respectiva comunicação científica. Não podemos nos perder no anseio da "produção pela produção" (LIMA e VIANA, 2017).

No mesmo sentido, os produtos educacionais oriundos de cada dissertação (Quadro 1), que caracterizam o Mestrado Profissional em Ensino, diferenciando-o do Mestrado Acadêmico, foram publicados e podem ser visualizados conforme os endereços eletrônicos a seguir: Dissertação $A$ (Disponível em: <https://editoracrv.com.br/produtos/detalhes/32319mudancas-climaticas globais-e-ensino-na-amazoniabr-uma-experiencia-comalunos-de-graduacao $>$ ) (Figura 1A), Dissertação B (Disponível em: <https://editoracrv.com.br/produtos/detalhes/32931-cartilha-amigos-do-solo>) (Figura 1B), Dissertação C (Disponível em: $<$ https://editoracrv.com.br/produtos/detalhes/32958-guia-didaticobrorigem formacao-e-erosao-do-solobruma-proposta-para-o-processo-de-ensino-e- 
aprendizagem>) (Figura 1C), Dissertação D (Disponível em: <https://editoracrv.com.br/produtos/detalhes/34022-guia-parainstrumentalizacao-de-trilhas-interpretativas-numa-perspectiva-de-ensino-eaprendizagem $>$ ) (Figura 1D), Dissertação E (Disponível em: $<$ https://editoracrv.com.br/produtos/detalhes/34113-proposta-didatica-para-oensino-de-meio-ambiente-e-agua>) (Figura 1E). Entretanto, o produto da Dissertação $F$ está somente disponível em: <https://drive.google.com/file/d/1xY4orXD0RcgWU5a_zwZXxZNin07ZP3F/vie $\underline{\mathrm{w}}>$ (Figura 1F).

Figura 1: Imagens das capas dos produtos publicados.

A
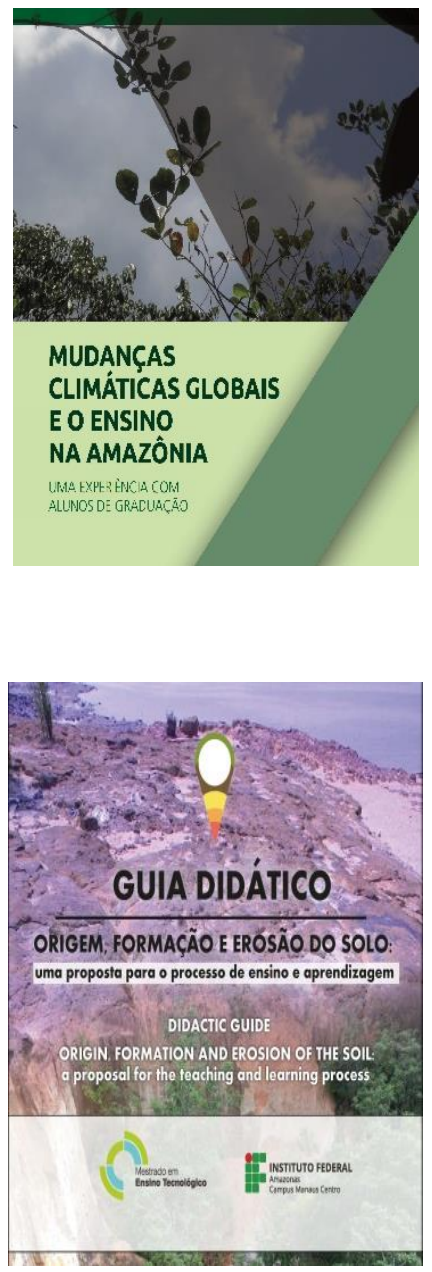

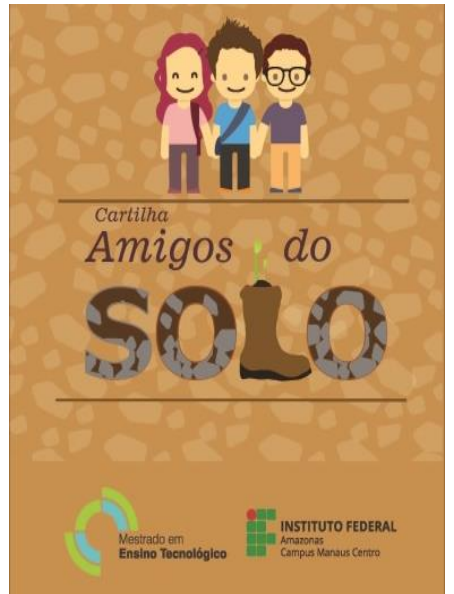

B

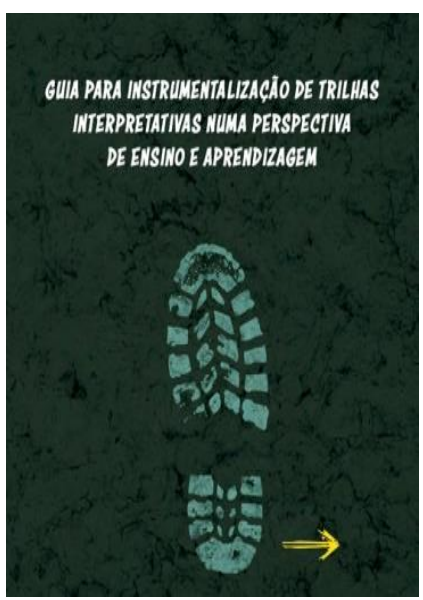

C

D 


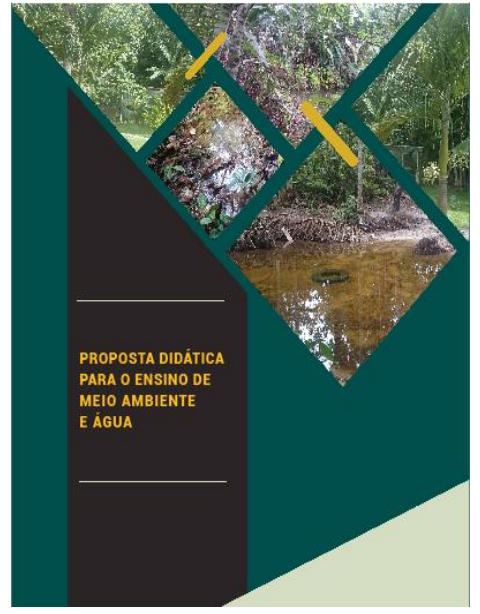

E

Fontes: <https://editoracrv.com.br/produtos>; <http://ppget.ifam.edu.br/dissertacoesdefendidas $>$.

Acesso em: 15 de setembro de 2020.

Produtos educacionais segundo a CAPES (BRASIL, 2013) podem ser caracterizados como processos ou produtos educativos utilizados e utilizáveis em condições reais de ensino, como protótipo ou de cunho artesanal. Com vistas na utilização dos produtos educacionais elaborados pela sociedade, todos os aqui analisados demonstram estarem em consonância com os problemas e exigências da sociedade contemporânea no ato de abordar temáticas como mudanças climáticas globais, preservação e conservação do solo, origem e formação e erosão do solo, trilha interpretativa, meio ambiente e água e, por fim, paisagem (Quadro 1). Em todos eles, o solo está presente como objeto de estudo e abordado na busca de uma alternativa viável para minimizar e/ou resolver problemas ambientais quanto ao seu uso, manejo e ocupação numa perspectiva sustentável com o intuito da melhoria da qualidade de vida dos que nele habitam e na sua própria saúde ambiental.

Os problemas complexos e suas resoluções definem um anova tradição de pesquisa em um novo tempo, de integração global, de sociedade em rede, com identidades científicas abrangentes, reconstruções nas delimitações dos campos de saberes. Assim, a interdisciplinaridade tem papel estratégico no sentido de estabelecer a relação entre os saberes, propor o encontro entre ciência e arte, apresentando-se, assim, como um conhecimento que responde aos desafios do saber complexo (BRASIL, 2013).

Assim, os produtos educacionais apresentam características regionais contextualizados ao Bioma Amazônia, apresentando temáticas atuais que muitas vezes são difíceis de serem encontradas em fontes bibliográficas comuns devido as suas especificidades com potencial de inserção na Educação Básica (4) e Ensino Superior (2) (Quadro 1) oportunizando melhoria no contexto educacional amazônico e contribuindo para a formação 
profissional na região. Percebe-se que o professor orientador em solos na educação profissional tem grande relevância, pois é responsável pelo desenvolvimento de pesquisas que podem ser aplicadas nas mais diversas modalidades de ensino, com diferentes objetivos, seguindo diferentes processos, técnicas, recursos, estratégias de caráter interdisciplinar, e acima de tudo, implementados para atender a necessidade frente à realidade da Região Amazônica, com uma grande biodiversidade em regiões longínquas.

\section{CONSIDERAÇÕES FINAIS}

A Educação em Solo na Pós Graduação em Ensino Tecnológico é representada por pesquisas científicas e produtos educacionais aplicados a educação básica e superior com caráter investigativo, problematizador, exploratório e interdisciplinar, com forte valorização da teoria e prática para a promoção da educação e, acima tudo, para estabelecer as relações necessárias com a realidade no qual alunos, professores e sociedade como 0 todo estão inseridos.

As dissertações desenvolvidas dependem fundamentalmente da adoção de atividades práticas, já que englobam temáticas especificas do Bioma Amazônia, que são melhor compreendidas a partir do contato do pesquisador com o objeto pesquisado e conduzem a um ensino e aprendizado com autonomia, capacidade de crítica, raciocínio e habilidades cognitivas.

Os produtos educacionais apresentam características regionais contextualizados ao Bioma Amazônia em consonância com os problemas e exigências da sociedade contemporânea, numa perspectiva sustentável com o intuito da melhoria da qualidade de vida dos que nele habitam e na sua própria saúde ambiental. Ainda oportunizam processos e produtos tecnológicos sustentáveis adequados ao contexto educacional amazônico promovendo a formação profissional tecnológica na região e proporcionando melhoria da qualidade de vida e qualidade ambiental.

É preciso continuar os estudos na Educação em Solos, ampliando as pesquisas nas mais diferentes modalidades de ensino com o intuito de buscar recursos e estratégias que maximizem o seu processo de ensino e aprendizagem conjuntamente com valores morais, éticos e atitudes sustentáveis associados ao Bioma no qual está inserido.

Por fim, o educador e o educando em solo são os principais responsáveis para o êxito na condução das pesquisas em solo no ensino tecnológico, já que devem dialogar sobre as experiências vividas para assim fortalecer a educação em solo na sociedade.

\section{REFERÊNCIAS}


ALVES, A.O.; SOUZA, M.I.A. A geografia nos anos iniciais: a leitura integrada da paisagem para a construção de conceitos dos conteúdos relevo-solorocha. Revista Brasileira de Educação em Geografia, v. 5, n. 10, p. 277 299, 2015. Disponível em:<http://www.revistaedugeo.com.br/ojs/index.php/revistaedugeo/article/vie wFile/329/17>.Acesso em: 29 jan. 2020.

BIONDI, D.; FALKOWSKI, V. Avaliação de uma atividade de educação ambiental com o tema "solo". Revista Eletrônica do Mestrado em Educação Ambiental, v. 22. p. 202-215, 2009. Rio Grande: FURG, 2009. Disponível em: <http://www.remea.furg.br/vol22/art15vol22.pdf>. Acesso em: ago. 2020.

BOGDAN, R.; BIKLEN, S. Investigação qualitativa em educação: Uma introdução à teoria e aos métodos. Portugal: Porto Editora, 1994.

BOTELHO, J. S.; MARQUES, J. D. O.; OLIVEIRA, A. N. S. Experimentos em laboratório para o ensino sobre solos na disciplina de geografia. Educitec, v. 5, n. 10, p. 228-248, 2019.

BOTELHO, J.S.; MARQUES, J.D.O. O ensino de solo na Geografia a partir da prática em campo. Revista de Estudos e Pesquisas sobre Ensino Tecnológico, v. 6, Edição Especial, p. 1-21, 2020.

BRASIL. Ministério da Educação. Secretaria de Educação à Distância. Objetos de aprendizagem: uma proposta de recurso pedagógico. Brasília: MEC/SEED, 2007.

BRASIL. Coordenação de Aperfeiçoamento de Pessoal de Nível Superior. Documento de área 2013. Brasília: CAPES, 2013. Disponível em: <http://www.capes.gov.br/ensino_doc_area_e_comissão.pdf>. Acesso em: 18 jul. 2020.

BRASIL. Coordenação de Aperfeiçoamento de Pessoal de Nível Superior. Documento de Área-Ensino. 2016. Disponível em:

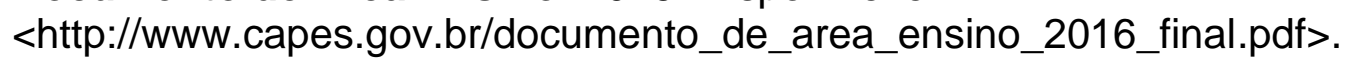
Acesso em: 20 set. 2020.

BRASIL. Coordenação de Aperfeiçoamento de Pessoal de Nível Superior. Portaria $\mathbf{N}^{\circ} \mathbf{6 0}$ de 20 de março de 2019. Dispõe sobre o mestrado e doutorado profissionais, no âmbito da Coordenação de Aperfeiçoamento de Pessoal de Nível Superior. Diário Oficial [da] República Federativa do Brasil, Brasília, DF, 22 mar. 2019. № 56, Seção I, p. 1. ISSN 1677-7042. Disponível em:<http://www.capes.gov.br/portarias/22032019_portarias_59e60.pdf>.Aces sado em: 18 set. 2020.

BRASIL. Ministério da Educação. Resolução CNE/CES 7/2017. Diário Oficial da União, Brasília, 12 de dezembro de 2017a, Seção 1, p. 21. Disponível em: <http://www.portal.mec.gov.br/rces007_17>. Acessado em: 18 set. 2020. 
BRASIL. Ministério da Educação. PORTARIA № 389 de 23 de março de 2017. Dispõe sobre o mestrado e doutorado profissional no âmbito da pósgraduação stricto sensu. Diário Oficial da União, Brasília, 24 de março de 2017b, № 58, Seção 1, p. 61. ISSN 1677-7042. Disponível em: <http://www.portal.mec.gov.br/Portaria389-2017_doutoradoprofissional.pdf>. Acessado em: 17 set. 2020.

BRASIL. Ministério da Educação. Cursos de Educação Profissional Tecnológica de Graduação e Pós-Graduação. Disponível em: $<$ http://portal.mec.gov.br/cursos-da-ept/educacao-profissional-tecnologica-degraduacao-e-de-pos-graduacao> Acessado em: 15 de set. 2020.

BREVIK, E.C.; ABIT, S., BROWN, D.; DOLLIVER, H.; HOPKINS, D.; LINDBO, D.; MANU, A.; MBILA, M.; PARIKH, S.J.; SCHULZE, D.; SHAW, J.; WEIL, R.; AND WEINDORF, D. Soil science education in the United States: history and current enrollment trends. Journal Indian Society Soil Science, v.62, p.299306, 2014.

BREVIK, E.C.; HARTEMINK, A.E. Early soil knowledge and the birth and development of soil science. Catena, v. 83, p. 23-33, 2010.

CERETTA, C. A.; ANJOS, L. H. C. DOS; SIQUEIRA, J. O. A pós-graduação em Ciência do Solo no Brasil: evolução e tendência. Revista Brasileira de Pós-Graduação, v. 5, n. 9, p.7-35, 2008.

DEMO, P. Habilidades do Século XXI. Boletim Técnico do Senac. Rio de Janeiro, v. 34, n. 2, maio/ago. 2008. Disponível em:

<http://pedrodemo.sites.uol.com.br/>. Acesso em 15 ago. 2020.

DENZIN, N. K.; LINCOLN, Y. S. Introdução: a disciplina e a prática da pesquisa qualitativa. In: DENZIN, N. K.;LINCOLN, Y. S. (Orgs.). 0 planejamento da pesquisa qualitativa: teorias e abordagens. 2. ed. p. 1541. Porto Alegre: Artmed, 2006.

DOS SANTOS, A.L.F.; AZEVEDO, J.M.L. de. A pós-graduação no Brasil, a pesquisa em educação e os estudos sobre a política educacional: os contornos da constituição de um campo acadêmico. Revista Brasileira de Educação, v. 14 n. 42 , p. 535-605, 2009.

FIELD, D.J.; KOPPI, A.J.; JARRETT, L.E.; ABBOTT, L.K.; CATTLE, S.R.; GRANT, C.D.; MCBRATNEY, A.B.; MENZIES, N.W.; WEATHERLEY, A.J. Soil science teaching principles. Geoderma, v.167-68, p. 9-14, 2011.

FURTADO, T. B.; ESMIN, A. A. A.; OLIVEIRA, N. Técnica de recomendação e recuperação de conteúdo para repositórios institucionais baseado na universidade federal de lavras (UFLA). In: CONFERÊNCIA LUSOBRASILEIRA SOBRE ACESSO ABERTO, 5., 2014, Coimbra. Anais eletrônicos... Coimbra: Universidade de Coimbra, 2014. 
JACON, M. do C. Prática Pedagógica na Educação Profissional e Tecnológica: reflexões à luz de teorias modernas e contemporâneas. XII WORKSHOP DE PÓS-GRADUAÇÃO E PESQUISA DO CENTRO PAULA SOUZA. São Paulo, 03 - 05 de outubro de 2017. ISSN: 2175-1897

LELIS, J. L.; LOBO, L.M.; MUGGLER, C.C.; CAON, K.G.; CAMPO, J.L.A.; PEREIRA, D.M.; VILLAR, J.P.; HENRIQUE, E.M.; PRIMO, M.F. Discutindo solo na escola: construção de conceitos e valores ambientais. Revista Brasileira de Agroecologia, v. 2, p. 559-562, 2007.

KREUTZ, D. H.; WELTER, C. B. Professor em (Re) Construção: Reflexões de um docente em formação pedagógica. Revista Brasileira da Educação Profissional e Tecnológica, v. 2, n. 11, p. 13-24, 2016.

LIMA, M. de O.; VIANA, G.M.R. Divulgação científica: responsabilidade e importância. Rev Pan-Amaz Saude, v. 8, n. 4, p. 7-8, 2017. LIMA, E.S dos S.; MARQUES, J.D.O. Proposta didática para o ensino de meio ambiente e água. Curitiba: CRV, 2019. 93p.

MACHADO, L. R. de S. Diferenciais inovadores na formação de professores para a educação profissional. Revista Brasileira da Educação Profissional e Tecnológica, Brasília, v. 1, n. 1, p.8-22 jun. 2008.

MARQUES, J.D.O.; PAES, L.S. da; BOMFIM, S.A.A. Abordagem muldisciplinar do esino de solo a partir da experiência docente. In:GONZAGA, A. M. Formação de professores no ensino tecnológico: fundamentos e desafios, Curitiba: CRV, 2015, p. 131-146.

MARQUES, S.; OLIVEIRA, T. Educação, ensino e docência: reflexões e perspectivas. Revista Reflexão e Ação, Santa Cruz do Sul, v. 24, p. 189211, 2016.

MAYRING, P. Introdução à pesquisa social qualitativa. 5. ed Weinheim: Beltz, 2002. 82p.

MORAIS, J. de M,. SOUZA, P.; COSTA, T. A relação teoria e prática: investigando as compreensões de professores que atuam na educação profissional. Revista Brasileira de Educação Profissional Tecnológica, v. 1, n.2, p. 111-124, 2017.

MEGONIGAL, J. P.; STARRS, B. S. S.; PEKARIK, A.; DROHAN, P.; HAVLIN, J. "Dig It!": How an Exhibit Breathed Life into Soils Education. v. 74, p. 706-716, 2010.

MUGGLER,C.C.;SOBRINHO.F.A.P.; MACHADO.V.A. Educação em solos:

Princípios, Teoria e Métodos. Revista Brasileira de Ciência Solo, v.30, p.733740, 2006. 
OLIVEIRA, A. N. S.; MARQUES, J. D. DE O. Aula de campo no ensino de solos. Revista de Estudos e Pesquisas sobre Ensino Tecnológico. Educitec, v. 3, n.5, p. 33-47, 2017.

OLIVEIRA, A. N. S.; MARQUES J. D. de O.; PAES, L. da S. Percepção ambiental sobre sustentabilidade do solo. EDUCERE - Revista da Educação, v. 17, n. 1, p. 93-120, 2017.

PATRUS, R.; LIMA, M. C. A formação de professores e de pesquisadores em administração: contradições e alternativas. Revista Economia \& Gestão, v. 14, n. 34, p. 4-29, 2014.

REHEM, C. O professor da educação profissional: que perfil corresponde aos desafios contemporâneos? Boletim Técnico do Senac. 2016. 10p.

Disponível em:

<http://www.senac.br/informativo/BTS311/boltec311/.htm>Acesso em: 20 ago. 2020.

RIEDER, A. Fração ideal da carga horária com aulas de campo, laboratório e sala no ensino de solos: visão do aluno. Ciência \& Educação, v. 20, n. 1, p. 207-226, 2014.

SANTOS, S. C. O processo de ensino-aprendizagem e a relação professoraluno: aplicação dos sete princípios para a boa prática na educação de ensino superior. Caderno de Pesquisas em Administração, v. 8, n. 1, p. 6982, 2001.

SANTOS, A. P.; AZEVEDO, R. O. M. Saberes docentes na educação profissional técnica de nível médio: uma proposta para a formação de professores do IFAM - Campus Lábrea. Revista Brasileira da Educação Profissional e Tecnológica, v. 2, n. 11, p. 36-50, 2016.

SAVIANI, D. Trabalho e educação: fundamentos ontológicos e históricos. Revista Brasileira de Educação, Rio de Janeiro, v. 12, n. 34, p. 152-165, 2007.

SEVERINO, A. J. Premissas e desafios da pesquisa na Pós-Graduação em Educação: da relevância social ao cuidado epistemológico. In: ENCONTRO DE PESQUISA DISCENTE DO PROGRAMA DE PÓS-GRADUAÇÃO EM EDUCAÇÃO, 4., 2006, São Paulo. Anais... São Paulo: UNINOVE, 2006.

SOUZA, H. F. T.; MATOS, F. S. O ensino dos solos no ensino médio: desafios e possibilidades na perspectiva dos docentes. Geosaberes, Fortaleza, v. 3, n. 6, p. 71-78, 2012.

STAKE, R. E. Estudos de caso em pesquisa e avaliação educacional. Educação e seleção, n. 7, p. 5-14, 2013. Disponível em: http://www.fcc.org.br/pesquisa/publicacoes/es/artigos/55.pdf. Acesso em: 25 ago. 2020. 
TILMAN, D.; FARGIONE, J.; WOLFF, B.; ANTONIO, C.D.; DOBSON, A.; HOWARTH, R.; SCHINDLER, D.; SCHLESINGER, W.H.; SIMBERLOFF, D.; SWACKHAMER, D. Forecasting agriculturally driven global environmental change. Science, Pensilvânia, EUA, v. 292, p. 281-284, 2001.

TRIVIÑOS, A.N.S. Três enfoques na pesquisa em ciências sociais: o positivismo, a fenomenologia e o marxismo. TRIVIÑOS, A. N.S. In: Introdução à pesquisa em ciências sociais. São Paulo: Atlas, p. 30-79, 1987.

YIN, Robert K. Estudo de Caso: Planejamento e Métodos. Bookman editora, 2005.

ZINN, Y.L.; SKOPURA, A.L.A. Uma nova abordagem para o ensino sobre materiais de origem do solo. Cadernos de Ciência \& Tecnologia, Brasília, v. 32, n. 1/2, p. 229-244, 2015. 